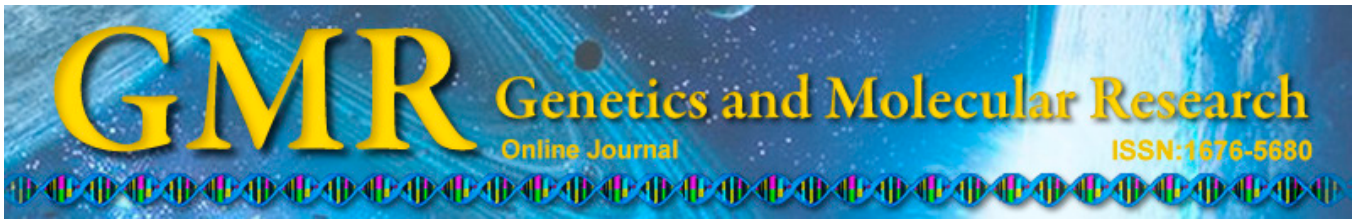

\title{
Effects of isoflurane preconditioning in the delayed phase on myocardial tumor necrosis factor alpha levels and caspase-3 protein expression in a rabbit model of ischemia-reperfusion injury
}

\author{
K. Ran ${ }^{1}$, D.Q. Zou ${ }^{1}$, Y.Y. Xiao', Y.T. Chang ${ }^{1}$, K.M. Duan ${ }^{2}$, Y.W. Ou ${ }^{2}$ and \\ Z.J. Li ${ }^{1}$ \\ ${ }^{1}$ Department of Anesthesiology, The Second Xiangya Hospital, \\ Central South University, Changsha, China \\ ${ }^{2}$ Department of Anesthesiology, The Third Xiangya Hospital, \\ Central South University, Changsha, China \\ Corresponding author: Z.J. Li \\ E-mail: xiaoyanying_xyy@163.com
}

Genet. Mol. Res. 14 (3): 7267-7273 (2015)

Received June 3, 2014

Accepted February 20, 2015

Published July 3, 2015

DOI http://dx.doi.org/10.4238/2015.July.3.1

\begin{abstract}
This study aimed to investigate the protective effects and the mechanisms underlying these effects of isoflurane preconditioning in the delayed phase of myocardial ischemia-reperfusion injury. We randomly divided 30 healthy male New Zealand white rabbits into three groups with 10 rabbits in each group as follows: sham operation group ( $\mathrm{C}$ group), ischemia-reperfusion group ( $\mathrm{I} / \mathrm{R}$ group), and $2.0 \%$ isoflurane preconditioning group ( $\mathrm{S}$ group). Rabbits in the $\mathrm{C}$ group received thoracotomy for $160 \mathrm{~min}$. Rabbits in the I/R group underwent left coronary artery occlusion for $40 \mathrm{~min}$ and reperfusion for $120 \mathrm{~min}$. Rabbits in the $\mathrm{S}$ group received inhalation of $2.0 \%$ isoflurane and $100 \%$ oxygen for $2 \mathrm{~h}$; after $24 \mathrm{~h}$, rabbits in this group
\end{abstract}


received the same treatment as that administered to rabbits in the $\mathrm{I} / \mathrm{R}$ group. We examined the tumor necrosis factor alpha (TNF- $\alpha$ ) levels in each group 20 min before occlusion of the left coronary, 20 and 40 min after occlusion of the left coronary artery, and 1 and $2 \mathrm{~h}$ after myocardial reperfusion. After reperfusion, immunoblotting was used to measure the myocardial caspase- 3 expression levels, and the infarct size was measured using Evans blue and tetrazolium chloride staining. The levels of TNF- $\alpha$ and caspase- 3 were lower in the S group than in the $\mathrm{I} / \mathrm{R}$ group, and the myocardial infarct size decreased in the $\mathrm{S}$ group. Thus, isoflurane preconditioning in the delayed phase exerted protective effects by decreasing the myocardial caspase-3 expression and TNF- $\alpha$ production in a rabbit model of ischemia-reperfusion injury.

Key words: Isoflurane; Preconditioning in delayed phase; Myocardial ischemia reperfusion; Caspase-3;

Tumor necrosis factor- $\alpha$

\section{INTRODUCTION}

Ischemia-reperfusion ( $\mathrm{I} / \mathrm{R})$ injury is an urgent clinical problem that needs to be addressed. Isoflurane pretreatment provides myocardial protection in the early phase (Symons and Myles, 2006). Previous studies have shown that isoflurane preconditioning induces a delayed protective effect on the myocardium (Tonkovic-Capin et al., 2002; Tanaka et al., 2004), but the specific mechanism underlying this effect has not been elucidated to date. Caspase-3 is an important intracellular pro-apoptotic protein that regulates apoptosis; caspase-3 plays an important role in I/R injury (Takahashi, 1999). Whether the protective effects of isoflurane preconditioning in the delayed phase are associated with apoptosis has not been clarified thus far. Therefore, this study aimed to determine the myocardial protective effects of isoflurane preconditioning in the delayed phase on the expression of caspase-3 and the level of the pro-inflammatory cytokine tumor necrosis factor alpha $(\mathrm{TNF}-\alpha)$ in a rabbit model of $\mathrm{I} / \mathrm{R}$ injury.

\section{MATERIAL AND METHODS}

\section{Materials}

Caspase-3 (CPP32) Ab-4 (rabbit polyclonal antibody) was purchased from Lab Vision (Värmdö, Sweden). Evans blue, nitroblue tetrazolium chloride (TTC), sodium pentobarbital, and acrylamide were purchased from Sigma (USA). Horseradish peroxidase labeled goat anti-rabbit immunoglobulin $\mathrm{G}(\mathrm{IgG} ; 1.0 \mathrm{mg} / \mathrm{mL})$ and TNF- $\alpha$ enzyme-linked immunosorbent assay (ELISA) kit were purchased from Jingmei (Shenzhen). Anhydrous ethanol, isopropyl alcohol, chloroform, xylene, agarose, and Tris were purchased from a Bioteck (Beijing, China). 


\section{Methods}

\section{Preparation of an I/R model}

Rabbits were anesthetized by injecting $30 \mathrm{mg} / \mathrm{kg}$ sodium pentobarbital to in the ear vein; after fixation, tracheotomy and intubation were performed for mechanical ventilation with pure oxygen, the tidal volume was $15 \mathrm{~mL} / \mathrm{kg}$, and the respiratory rate was 35 breaths/ min. Thoracotomy was performed on fourth intercostal space of the left anterior artery, the pericardium was cut open, the middle part of the left coronary artery was blocked using a silk ligature to block the blood flow and induce myocardial ischemia. The ischemic ventricular wall showed cyanosis and bulging accompanied with ST-segment elevation in the electrocardiogram.

\section{Animal grouping}

Thirty healthy male New Zealand white rabbits weighing $2.0-2.5 \mathrm{~kg}$ were provided by the Animal Department of Xiangya Medical College. The rabbits were randomly divided into three groups with 10 rabbits in each group as follows: sham operation group (C group), $\mathrm{I} / \mathrm{R}$ group, and $2.0 \%$ isoflurane preconditioning group ( $\mathrm{S}$ group). Rabbits in $\mathrm{C}$ group received inhalation of $100 \%$ oxygen for $2 \mathrm{~h}$; after $24 \mathrm{~h}$, the left coronary was lined without blocking for $160 \mathrm{~min}$. Rabbits in the I/R group received inhalation of $100 \%$ oxygen for $2 \mathrm{~h}$; after $24 \mathrm{~h}$, the left descending artery was blocked for $40 \mathrm{~min}$ and reperfused for $120 \mathrm{~min}$. Rabbits in the $\mathrm{S}$ group received inhalation of $2.0 \%$ isoflurane and $100 \%$ oxygen for $2 \mathrm{~h}$; after $24 \mathrm{~h}$, the treatment as that in the $\mathrm{I} / \mathrm{R}$ group was administered to rabbits in this group.

\section{Detection of indicators}

\section{Determination of TNF- $\alpha$ levels}

TNF- $\alpha$ levels in the internal carotid arterial blood in each group were measured 20 min before occlusion of the left descending coronary artery (T1), 20 min after occlusion of the left descending coronary artery (T2), 40 min after occlusion of the left descending coronary artery (T3), $1 \mathrm{~h}$ after the myocardial reperfusion (T4), and $2 \mathrm{~h}$ after the myocardial reperfusion (T5) using sandwich ELISA.

\section{Measurement of the myocardial infarct size}

The coronary artery was blocked again $2 \mathrm{~h}$ after reperfusion, and $2 \mathrm{~mL} \mathrm{2 \%}$ Evans blue was injected in the internal carotid artery to stain the myocardium and to differentiate between the ischemic (non-blue) and non-ischemic (blue) tissues. The hearts were quickly removed and horizontally cut into approximately $2-\mathrm{mm}$ slices; the thin slices of the myocardium were dried using filter papers, the right ventricle and the non-ischemic tissue was cut off, and the quality of the remaining tissue was examined. The slices of the ischemic myocardium were incubated with $0.5 \%$ TTC phosphate buffer, $\mathrm{pH} 7.4$, at $37^{\circ} \mathrm{C}$ for 15 min to determine the infarct tissues. We separated and measured the quality of the necrotic areas (gray-white) and 
non-necrotic areas (dark red). Ischemia and the myocardial infarct size was calculated as a percentage of the total left ventricular mass.

\section{Western blot analysis of the myocardial tissue}

Myocardial proteins were extracted according to a previously described method (Wang et al., 2006). The extracted myocardial proteins were stored at $-70^{\circ} \mathrm{C}$ for further analysis. Polyacrylamide gel electrophoresis using $12.5 \%$ sodium dodecyl sulfate was performed on each sample containing $100 \mu \mathrm{g}$ myocardial proteins. The isolated myocardial proteins were transferred to a polyvinylidene difluoride membrane using the Pharmacia Nova Blot power transfer device for $3 \mathrm{~h}$ at room temperature. Rabbit anti-caspase- 3 antibody was added and the membrane was incubated overnight at $4^{\circ} \mathrm{C}$. Then, the membranes were washed with TTBS buffer for 15 min 4 times and anti-goat anti-rabbit IgG was added; subsequently, the membranes were shaken and incubated at room temperature for $1 \mathrm{~h}$. After washing with TTBS buffer thoroughly, enhanced chemiluminescence reaction was performed. The results were scanned and analyzed using GIS-700-type gel image system, and the average gray values were documented.

\section{Statistical analysis}

All data are reported as means \pm standard deviation; one-way ANOVA was performed using the SPSS13.0 statistical software. A difference of $\mathrm{P}<0.05$ was considered to be statistically significant.

\section{RESULTS}

\section{Changes in the serum TNF- $\alpha$ levels}

Compared to the $\mathrm{C}$ group, the $\mathrm{I} / \mathrm{R}$ and $\mathrm{S}$ groups showed a significant increase in the serum TNF- $\alpha$ levels after $\mathrm{I} / \mathrm{R}$ injury $(\mathrm{P}<0.05)$. However, the TNF- $\alpha$ levels in the $\mathrm{S}$ group were significantly lower than those in the $\mathrm{I} / \mathrm{R}$ group $(\mathrm{P}<0.05$; Table 1$)$.

Table 1. Changes in the serum tumor necrosis factor alpha (TNF- $\alpha$ ) levels in each group (pg/mL, means \pm SD).

\begin{tabular}{llcccc}
\hline Group & T1 & T2 & T3 & T4 & T5 \\
\hline C group & $52.3 \pm 6.7$ & $54.2 \pm 4.5$ & $53.7 \pm 3.1$ & $54.6 \pm 4.2$ & $51.5 \pm 5.6$ \\
I/R group & $54.1 \pm 5.3$ & $78.6 \pm 6.4$ & $88.1 \pm 7.9^{*}$ & $110.5 \pm 9.4^{*}$ & $157.6 \pm 5.5^{*}$ \\
S group & $53.5 \pm 7.2$ & $63.3 \pm 5.7$ & $75.4 \pm 4.4^{*}$ & $92.5 \pm 8.3^{*} \Delta$ & $105.8 \pm 7.6^{* \Delta}$ \\
\hline
\end{tabular}

*Compared to $\mathrm{C}$ group, $\mathrm{P}<0.05 ;{ }^{\triangle}$ compared with $\mathrm{I} / \mathrm{R}$ group, $\mathrm{P}<0.05$.

\section{Changes in the myocardial infarct size}

No significant difference was observed in the ischemic area between the $I / R$ and $S$ groups $(\mathrm{P}>0.05)$. However, the infarct size in the $\mathrm{S}$ group was significantly smaller than that in the $\mathrm{I} / \mathrm{R}$ group $(\mathrm{P}<0.01$; Table 2$)$. 
Table 2. Myocardial infarct size and ischemic area (means $\pm \mathrm{SD}, \mathrm{N}=10$ ).

\begin{tabular}{lccccc}
\hline Group & Left ventricular myocardial $(\mathrm{g})$ & Ischemic myocardium $(\mathrm{g})$ & Infarcted myocardium $(\mathrm{g})$ & Ischemic area $(\%)$ & Infarcted area $(\%)$ \\
\hline C group & $3.16 \pm 0.68$ & - & - & - & - \\
I/R group & $2.93 \pm 0.44$ & $0.88 \pm 0.35$ & $0.33 \pm 0.06$ & $33.6 \pm 3.1$ & $37.8 \pm 1.7$ \\
S group & $3.12 \pm 0.73$ & $1.07 \pm 0.32$ & $0.21 \pm 0.05$ & $34.3 \pm 2.2^{*}$ & $19.7 \pm 2.8^{\triangle}$ \\
\hline
\end{tabular}

*Compared to I/R group, $\mathrm{P}<0.05 ;{ }^{\triangle}$ compared to I/R group, $\mathrm{P}<0.05$.

\section{Effects of isoflurane preconditioning in the delayed phase on myocardial expression of caspase-3}

The expression level of myocardial caspase- 3 was low in the $C$ group; caspase- 3 expression increased in the $\mathrm{I} / \mathrm{R}$ and $\mathrm{S}$ groups after $\mathrm{I} / \mathrm{R}(\mathrm{P}<0.05)$, but the level of myocardial caspase-3 expression in the $\mathrm{S}$ group was significantly lower than that in the $\mathrm{I} / \mathrm{R}$ group $(\mathrm{P}<$ 0.05; Table 3 and Figure 1).

Table 3. Expression of myocardial caspase-3 in rabbits of different groups.

\begin{tabular}{lc}
\hline Group & Caspase-3 levels \\
\hline C group & $24.3 \pm 2.8$ \\
I/R group & $60.8 \pm 2.2$ \\
S group & $44.5 \pm 3.4 * \Delta$ \\
\hline
\end{tabular}

*Compared to $\mathrm{C}$ group, $\mathrm{P}<0.05 ;{ }^{\triangle}$ compared to I/R group, $\mathrm{P}<0.05$.

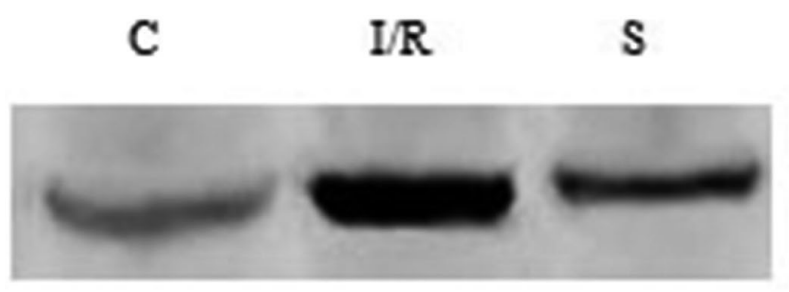

Activated caspase- 3

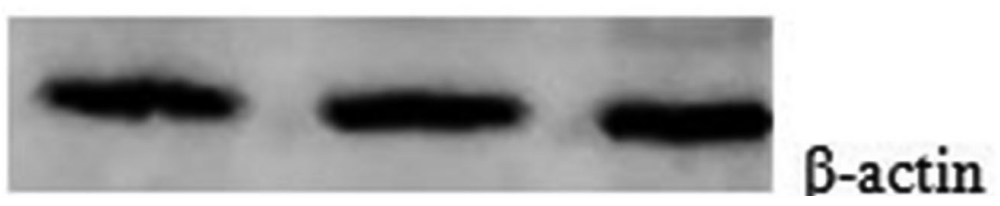

Figure 1. Immunoblot strips of activated caspase-3 in the myocardium of rabbits in different groups.

\section{DISCUSSION}

One of the mechanisms underlying I/R injury is the excessive inflammatory response. TNF- $\alpha$ is a major pro-inflammatory factor involved in the inflammatory responses in the body. TNF- $\alpha$ is a critical factor in the process of myocardial I/R injury, and rapid generation of TNF- $\alpha$ results in a cascade of expression of pro-inflammatory cytokines, which increase the 
inflammatory response (Sack et al., 2000). During I/R injury, the release of TNF- $\alpha$ increases, and thus, activates the aggregation and expression of polymorphonuclear leukocytes, intercellular adhesion molecule-1, and vascular cell adhesion molecule in the ischemic area and increases the accumulation of neutrophils and release of proteolytic enzymes, which may cause cell membrane damage, cell autolysis, and ultimately result in myocardial injury (Frangogiannis et al., 2002). In this study, isoflurane preconditioning in the delayed phase significantly decreased the production of serum TNF- $\alpha$ and the infarct size, which suggests that isoflurane preconditioning in the delayed phase may exert protective effects on the myocardium by inhibiting the production of TNF- $\alpha$ and decreasing inflammation in I/R injury.

Apoptosis, also known as programmed cell death, was first proposed by Kerr et al. (1972). Under certain physiological or pathological conditions, the cell triggers internal mechanisms such as activation of endogenous DNA endonuclease and undergoes apoptosis. The entire process of cell death involves a series of expression of specific genes followed by morphological and biochemical changes in the cell. Previous studies have shown that I/R not only can lead to necrosis of the myocardial cells, but also can induce apoptosis of cardiomyocytes (Fliss and Gatinger, 1996; Oliveti et al., 1996). One of the most critical factors involved in the mechanism of apoptosis is the activation of caspase family proteases. This family of proteases belongs to a group of aspartate-specific cysteine proteases, which can be sequentially activated by a protease cascade reaction; caspases play a key role in the process of apoptosis. Caspase- 3 is one of the important molecules of the caspase family that plays an important role in the process of apoptosis. Caspase-3 is usually present as an inactive zymogen in the cytoplasm. Upon stimulation with a variety of apoptotic signals and proteolysis, caspase- 3 is converted to its activated form, which may degrade a variety of protein substrates and thus plays a key role in the apoptotic process (Takahashi, 1999).

Our results showed that compared to the $\mathrm{I} / \mathrm{R}$ group, the group receiving isoflurane preconditioning in the delayed phase group had lower levels of myocardial caspase-3, which suggested that isoflurane preconditioning may decrease $\mathrm{I} / \mathrm{R}$-induced myocardial apoptosis and exert protective effects on the myocardium by downregulating the expression of caspase- 3 . Our results were consistent with those of Moolman et al. (2006). Moolman et al. reported that I/R activated p38 mitogen-activated protein kinase (MAPK) and increased the expression of the apoptotic protein caspase-3, and therefore, inhibition of p38 MAPK decreased the expression of the myocardial apoptotic protein caspase-3.

In summary, isoflurane preconditioning exerts protective effects on myocardial I/R injury by inhibition of TNF- $\alpha$ expression, reduction of the inflammatory response, and decrease in the expression of caspase-3 protein, which finally inhibits the myocardial apoptotic pathway.

\section{ACKNOWLEDGMENTS}

Research supported by the Science and Technology Bureau Projects of Changsha, Hunan (\#K1003049-31) and Hunan Provincial Health Department Project (\#B2011-029).

\section{REFERENCES}

Fliss H and Gatinger D (1996). Apoptosis in ischemic and reperfused rat myocardium. Circ. Res. 79: 949-956. Frangogiannis NG, Smith CW and Entman ML (2002). The inflammatory response in myocardial infarction. Cardiovasc. Res. 53: 31-47. 
Kerr JF, Wyllie AH and Currie AR (1972). Apoptosis: a basic biological phenomenon with wide-ranging implications in tissue kinetics. Br. J. Cancer 26: 239-257.

Moolman JA, Hartley S, Van Wyk J, Marais E, et al. (2006). Inhibition of myocardial apoptosis by ischaemic and betaadrenergic preconditioning is dependent on p38 MAPK. Cardiovasc. Drugs Ther. 20: 13-25.

Oliveti G, Quaini F, Sala R, Lagrasta C, et al. (1996). Acute myocardial infarction in humans is associated with activation of programmed myocyte cell death in the surviving portion of the heart. J. Mol. Cell Cardiol. 28: 2005-2016.

Sack MN, Smith RM and Opie LH (2000). Tumor necrosis factor in myocardial hypertrophy and ischaemia - an antiapoptotic perspective. Cardiovasc. Res. 45: 688-695.

Symons JA and Myles PS (2006). Myocardial protection with volatile anaesthetic agents during coronary artery bypass surgery: a meta-analysis. Br. J. Anaesth. 97: 127-136.

Takahashi A (1999). Caspase: executioner and undertaker of apoptosis. Int. J. Hematol. 70: 226-232.

Tanaka K, Ludwig LM, Krolikowski JG, Alcindor D, et al. (2004). Isoflurane produces delayed preconditioning against myocardial ischemia and reperfusion injury: role of cyclooxygenase-2. Anesthesiology 100: 525-531.

Tonkovic-Capin M, Gross GJ, Bosnjak ZJ, Tweddell JS, et al. (2002). Delayed cardioprotection by isoflurane: role of K(ATP) channels. Am. J. Physiol. Heart Circ. Physiol. 283: H61-H68.

Wang M, Tsai BM, Reiger KM, Brown JW, et al. (2006). 17-Beta-estradiol decreases p38 MAPK-mediated myocardial inflammation and dysfunction following acute ischemia. J. Mol. Cell Cardiol. 40: 205-212. 